Check for updates

Cite this: RSC Adv., 2017, 7, 54078

\title{
Efficient non-doped blue organic light-emitting diodes: donor-acceptor type host materials $\uparrow$
}

\author{
Jayaraman Jayabharathi, (D)* Palanisamy Sujatha, Venugopal Thanikachalam, \\ Palanivel Jeeva and Pavadai Nethaji
}

The new blue light emitting materials, $(E)-4^{\prime}-(1-(4-(2-(1-($ naphthalen-1-yl)-1H-phenanthro[9,10- $d$ ] imidazol-2yl)vinyl)phenyl)-1H-phenanthro[9,10-d]imidazol-2-yl)- $N, N$-diphenyl-[1,1']-biphenyl-4-amine (NPI-PITPA), (E)4' - (1-(4-(2-(1-(4-methylnaphthalen-1-yl)-1H-phenanthro[9,10- $d$ ] imidazol-2-yl)vinyl)phenyl)-1H-phenanthro [9,10-d]imidazol-2-yl)-N,N-diphenyl-[1,1']-biphenyl-4-amine (MeNPI-PITPA) and (E)-4'-(1-(4-(2-(1-(4methoxynaphthalen-1-yl)-1H-phenanthro[9,10-d] imidazol-2-yl)vinyl)phenyl)-1H-phenanthro[9,10-d] imidazol2-yl)-N,N-diphenyl-[1,1']-biphenyl-4-amine (OMeNPI-PITPA) with dual charge transport properties have been synthesized and characterised. These compounds exhibit excellent thermal properties with very high glasstransition temperature and thus are favourable to form thin films under thermal evaporation for non-doped organic light-emitting diodes (OLEDs). The non-doped blue device based on OMeNPI-PITPA show maximum efficiencies $\left(\eta_{\text {ex }} 4.90 \% ; \eta_{\mathrm{c}} 5.90 \mathrm{~cd} \mathrm{~A}^{-1} ; \eta_{\mathrm{p}} 5.10 \mathrm{~lm} \mathrm{~W}^{-1}\right.$ ) at low turn-on voltage and the device performances show that the phenanthroimidazole unit is a tunable building block for carrier injection properties and that they also can be used as hosts for green phosphorescent OLEDs.

Received 24th October 2017 Accepted 16th November 2017

DOI: 10.1039/c7ra11732a

rsc.li/rsc-advances emissive layer in blue OLEDs. ${ }^{19-21}$ There is still a challenge to achieve full color OLEDs based on deep blue emitting materials.

Therefore, to develop the multi-functional organic materials that can be used as both emitter for blue OLEDs and hosts for green OLEDs, molecules with donor (D) and acceptor (A) or electron and hole transport moieties assembled together to form electron and hole transport channels are synthesised. The D-A molecule should have relatively weak charge transfer properties because of red shifted emission and the small singlet-triplet splitting should have high triplet excited state energy which is used to excite the green phosphorescent dopant. Our continuous interest to design and synthesize the ntype imidazole derivatives as OLED emitters to improve the efficiencies of devices, ${ }^{22-31}$ herein, we report the synthesis of a series of blue-emitting (E)-4'-(1-(4-(2-(1-(naphthalen-1-yl)-1Hphenanthro[9,10- $d]$ imidazol-2-yl)vinyl)phenyl)- $1 H$-phenanthro $[9,10-d]$ imidazol-2-yl)- $N, N$-diphenyl-[1,1']-biphenyl]-4-amine derivatives and their application as the emitter in nondoped devices and host materials for green OLEDs. These derivatives show higher thermal stability, proper carries barriers and balanced charge injection property.

\section{Experimental}

\subsection{Materials and measurements}

All commercially available reagents were purchased from Sigma-Aldrich. All reactions were performed under nitrogen atmosphere. NMR spectra were measured on Bruker $400 \mathrm{MHz}$ NMR spectrometer. The mass spectra was recorded on Agilent 
LCMS VL SD in electron ionization mode and electrochemical measurements were performed with $\mathrm{CHI}$ 630A potentiostat electrochemical analyzer with platinum electrode as the working electrode, platinum wire as the counter electrode and $\mathrm{Ag} / \mathrm{Ag}^{+}$electrode as the reference electrode at a scan rate of $100 \mathrm{mV} \mathrm{s}^{-1}$. About $0.1 \mathrm{M}$ solution of tetrabutylammoniumperchlorate in $\mathrm{CH}_{2} \mathrm{Cl}_{2}$ was used as supporting electrolyte. The UVvisible spectra was obtained with Perkin Elmer Lambda 35 UVvis spectrophotometer and corrected for background absorption due to solvent. Perkin Elmer Lambda 35 spectrophotometer with RSA-PE-20 integrating sphere attachment was used to record UV-vis diffuse reflectance spectra. The emission spectra were recorded by a Perkin Elmer LS55 fluorescence spectrometer. The absolute PL quantum yields were measured in dichloromethane using $0.5 \mathrm{M} \mathrm{H}_{2} \mathrm{SO}_{4}$ solution of quinine (0.54) as reference. The solid-state quantum yield on the quartz plate using an integrating sphere $\phi_{\mathrm{unk}}=\phi_{\mathrm{std}}\left(\frac{I_{\mathrm{unk}}}{I_{\mathrm{std}}}\right)\left(\frac{A_{\mathrm{std}}}{A_{\mathrm{unk}}}\right)\left(\frac{\eta_{\mathrm{unk}}}{\eta_{\mathrm{std}}}\right)^{2}$, where $\phi_{\text {unk }}$ is the radiative quantum yield of the sample, $\phi_{\text {std }}$ is the radiative quantum yield of the standard, $I_{\mathrm{unk}}$ and $I_{\mathrm{std}}$ are the integrated emission intensities of the sample and standard, respectively. $A_{\text {unk }}$ and $A_{\text {std }}$ are the absorbances of the sample and standard, respectively and $\eta_{\text {unk }}$ and $\eta_{\text {std }}$ are the indexes of refraction of the sample and standard solutions. Thermogravimetric analyses (TGA) was performed with NETZSCH-Geratebau Gmbh thermal analysis STA 409 PCO. The differential scanning calorimetric (DSC) analyses were made under nitrogen atmosphere $\left(100 \mathrm{~mL} \mathrm{~min}^{-1}\right)$. The sensitivity of the instrument was set at $0.01 \mu \mathrm{g}$ and the sample $(10 \mathrm{mg})$ was heated from 30 to $700{ }^{\circ} \mathrm{C}$ at the rate of 10 or 15 or $20 \mathrm{~K} \mathrm{~min}^{-1}$.

\subsection{Theoretical calculations}

The ground state geometries were optimized using density functional theory method with the Becke three-parameter hybrid exchange and the Lee-Yang-Parr correlation functional (B3LYP) and 6-31G* as basis set using Gaussian 09 software package. $^{32}$

\subsection{Devices fabrication}

The EL devices based on the of NPI-PITPA, MeNPI-PITPA and OMeNPI-PITPA were fabricated by vacuum deposition of organic materials at $5 \times 10^{-6}$ Torr on precleaned indium tin oxide glass substrate with resistance of $20 \Omega$ per square. Organic layers were deposited onto the substrate at a rate of $0.1 \mathrm{~nm} \mathrm{~s}^{-1}$. After organic film deposition LiF and $\mathrm{Al}$ were thermally evaporated onto the surface of organic layer. The thickness of the organic materials and the cathode layers were controlled using a quartz crystal thickness monitor. A series of fabricated devices (I-V) with multilayer configuration is as follows: (a) ITO/NPB (4,4'-bis[ $N$-(1-naphthyl)- $N$-phenylamino]biphenyl) $(50 \mathrm{~nm}) / \mathrm{NPI}-$ PITPA (I)/MeNPI-PITPA (II)/OMeNPI-PITPA (III) $(30 \mathrm{~nm}) / \mathrm{BCP}$ (2,9-dimethyl-4,7-diphenyl-1,10-phenanthroline) $(15 \mathrm{~nm}) / \mathrm{Alq}_{3}$ (tris(8-hydroxyquinolinato)aluminum) $(50 \mathrm{~nm}) / \mathrm{LiF}(1 \mathrm{~nm}) / \mathrm{Al}$ (100 nm): (b) ITO/HATCN (10 nm)/NPI-PITPA/MeNPI-PITPA/ OMeNPI-PITPA (60 nm)/HATCN $(10 \mathrm{~nm}) / \mathrm{LiF}(1 \mathrm{~nm}) / \mathrm{Al}(100$ $\mathrm{nm}$ ) (hole-only device IV): (c) ITO/TPBi $(10 \mathrm{~nm}) / \mathrm{NPI}-\mathrm{PITPA} /$
MeNPI-PITPA/OMeNPI-PITPA $\quad(60 \quad \mathrm{~nm}) / \mathrm{TPBi} \quad(10 \mathrm{~nm}) / \mathrm{LiF}$ $(1 \mathrm{~nm}) / \mathrm{Al}(100 \mathrm{~nm})$ (electron-only device $\mathrm{V})$. These NPI-PITPA, MeNPI-PITPA and OMeNPI-PITPA materials are employed as host materials for green phosphorescent dopants in the fabricated device with configuration of ITO/NPB (40 nm)/TCTA $(5 \mathrm{~nm}) /$ NPI-PITPA $(30 \mathrm{~nm}): 5 \mathrm{wt} \% \operatorname{Ir}(\mathrm{ppy})_{3}$ (VI)/MeNPI-PITPA $(30 \mathrm{~nm}): 5$ wt\% $\operatorname{Ir}(\text { ppy })_{3}$ (VII)/OMeNPI-PITPA $(30 \mathrm{~nm}): 5 \mathrm{wt} \%$ $\operatorname{Ir}(\text { ppy })_{3}($ VIII $) /$ TPBI $(50 \mathrm{~nm}) / \mathrm{LiF}(1 \mathrm{~nm}) / \mathrm{Al}(100 \mathrm{~nm})$. The electrical measurements of the devices I-VII were made simultaneously using a Keithley 2400 sourcemeter (Keithley, Cleveland, Ohio). The EL spectra of the devices were carried out in ambient atmosphere without further encapsulations.

\subsection{Synthesis of (E)-2-(4-nitrostyryl)-1-naphthyl-1H- phenanthro $[9,10-d]$ imidazole (NSPI)}

A mixture of phenanthrenequinone $(2.08 \mathrm{~g}, 10 \mathrm{mmol}), 4$-nitrocinnamaldehyde (1.51 g, $10 \mathrm{mmol})$, substituted naphthylamine (4.65 g, $50 \mathrm{mmol})$ and ammonium acetate $(3.08 \mathrm{~g}, 40 \mathrm{mmol})$ in ethanol $(25 \mathrm{~mL})$ was refluxed at $120{ }^{\circ} \mathrm{C}$ for $12 \mathrm{~h}$ under nitrogen atmosphere. The reaction mixture was cooled and poured into methanol. The separated yellowish green crude product was purified by column chromatography using hexane : ethylacetate as the eluent (Scheme S1 $\dagger$ ). Anal. calcd for $\mathrm{C}_{33} \mathrm{H}_{21} \mathrm{~N}_{3} \mathrm{O}_{2}$ : C, 80.62; H, 4.30; N, 8.58. Found: C, 80.58; H, 4.27; N, 8.55. ${ }^{1} \mathrm{H}$ NMR (400 MHz, $\left.\mathrm{CDCl}_{3}\right): \delta 6.82(\mathrm{~d}, J=16.2 \mathrm{~Hz}, 1 \mathrm{H}), 6.92(\mathrm{t}, 1 \mathrm{H})$, $7.14(\mathrm{~d}, J=15.5 \mathrm{~Hz}, 1 \mathrm{H}), 7.28-7.41(\mathrm{~m}, 6 \mathrm{H}), 7.62-7.76(\mathrm{~m}, 7 \mathrm{H})$, $8.02(\mathrm{~d}, J=8.6 \mathrm{~Hz}, 2 \mathrm{H}), 8.62(\mathrm{t}, 1 \mathrm{H}), 8.88(\mathrm{~d}, J=7.8 \mathrm{~Hz}, 2 \mathrm{H}) \cdot{ }^{13} \mathrm{C}$ NMR (100 MHz, $\left.\mathrm{CDCl}_{3}\right)$ : $\delta 114.21,121.41,122.82,123.28$, 124.76, 125.34, 125.62, 126.17, 126.32, 126.69, 126.94, 127.52, 127.97, 128.12, 128.43, 128.91, 130.46, 130.83, 135.61, 142.31, 147.43. MS: $\mathrm{m} / z .491 .08\left[\mathrm{M}^{+}\right]$; calcd 491.16 .

\subsection{Synthesis of $(E)$-2-(4-aminostyryl)-1-naphthyl-1H- phenanthro $[9,10-d]$ imidazole (NPI)}

A mixture of (E)-2-(4-nitrostyryl)-1-naphthyl-1H-phenanthro $[9,10-d]$ imidazole $(4.15 \mathrm{~g}, 10 \mathrm{mmol})$ and $10 \% \mathrm{Sn} / \mathrm{HCl}(250 \mathrm{mg})$ in $25 \mathrm{~mL}$ ethanol was refluxed under stirring and $80 \%$ hydrazine hydrate $(15 \mathrm{~mL})$ was added dropwise for $30 \mathrm{~min}$ and the stirring was continued for $12 \mathrm{~h}$. The reaction mixture was poured into water and neutralized with aqueous $\mathrm{HCl}$. The formed white product was recrystallized from ethanol : water mixture. Yield: $60 \%$. Anal. calcd for $\mathrm{C}_{33} \mathrm{H}_{23} \mathrm{~N}_{3}$ : C, 85.85; H, 5.04; N, 9.14. Found: $\mathrm{C}$, 85.82; H, 4.98; N, 9.08. ${ }^{1} \mathrm{H}$ NMR $\left(400 \mathrm{MHz}, \mathrm{CDCl}_{3}\right) \delta 6.38(\mathrm{~d}, J$ $=7.8 \mathrm{~Hz}, 2 \mathrm{H}), 6.52(\mathrm{~s}, 2 \mathrm{H}), 6.71(\mathrm{~d}, J=16.0 \mathrm{~Hz}, 2 \mathrm{H}), 6.91-7.02$ $(\mathrm{m}, 6 \mathrm{H}), 7.09(\mathrm{~d}, J=16.0 \mathrm{~Hz}, 1 \mathrm{H}), 7.42-7.58(\mathrm{~m}, 7 \mathrm{H}), 7.92(\mathrm{~d}, J=$ $8.4 \mathrm{~Hz}, 1 \mathrm{H}), 8.28(\mathrm{~d}, J=7.6 \mathrm{~Hz}, 2 \mathrm{H}) .{ }^{13} \mathrm{C} \mathrm{NMR}\left(100 \mathrm{MHz}, \mathrm{CDCl}_{3}\right)$ : $\delta 113.18,120.41,121.79,122.25,123.73,124.31,124.59,125.14$, 125.29, 125.66, 125.91, 126.49, 126.94, 127.09, 127.41, 127.88, 129.43, 129.89, 134.57, 141.28, 126.40. MS: $m / z .461 .17\left[\mathrm{M}^{+}\right]$; calcd 461.26 .

\section{6. (E)-4' -(1-(4-(2-(1-(Naphthalen-1-yl)-1H-phenanthro[9,10- $d$ ]imidazol-2-yl)vinyl)phenyl)-1 $H$-phenanthro $[9,10-d]$ imidazol- 2-yl)- $N, N$-diphenyl-[1,1']-biphenyl]-4-amine (NPI-PITPA)}

A mixture of phenanthrenequinone (0.416 g, $2 \mathrm{mmol}), 4^{\prime}-$ (diphenylamino)biphenyl-4-carbaldehyde (0.698 g, $2 \mathrm{mmol}),(E)$ - 
2-(4-aminostyryl)-1-naphthyl-1 $H$-phenanthro[9,10- $d]$ imidazole (1.16 g, $3 \mathrm{mmol})$, ammonium acetate $(1.54 \mathrm{~g}, 20 \mathrm{mmol})$ and glacial acetic acid $(25 \mathrm{~mL})$ was refluxed at $120{ }^{\circ} \mathrm{C}$ for $12 \mathrm{~h}$ under nitrogen atmosphere..$^{33,34,39}$ The reaction mixture was poured into methanol and the separated white solid was filtered off, washed with water and purified by column chromatography using $\mathrm{CH}_{2} \mathrm{Cl}_{2}$ as the eluent. Yield: 52\%. Anal. calcd for $\mathrm{C}_{72} \mathrm{H}_{47} \mathrm{~N}_{5}$ : C, 88.02; H, 4.84; N, 7.15. Found: C, 87.98; H, 4.77; N, 7.11. ${ }^{1} \mathrm{H}$ NMR (400 MHz, $\left.\mathrm{CDCl}_{3}\right) \delta 6.68(\mathrm{~d}, J=15.2 \mathrm{~Hz}, 2 \mathrm{H}), 6.79$ $(\mathrm{s}, 4 \mathrm{H}), 6.92(\mathrm{~d}, J=15.0 \mathrm{~Hz}, 1 \mathrm{H}), 7.12-7.47(\mathrm{~m}, 24 \mathrm{H}), 7.54(\mathrm{~d}, J=$ $8.9 \mathrm{~Hz}, 2 \mathrm{H}), 7.62-7.72(\mathrm{~m}, 10 \mathrm{H}), 8.32(\mathrm{~d}, J=7.8 \mathrm{~Hz}, 2 \mathrm{H}), 8.69(\mathrm{t}$, $2 \mathrm{H}) .{ }^{13} \mathrm{C} \mathrm{NMR}\left(100 \mathrm{MHz}, \mathrm{CDCl}_{3}\right): \delta$ 112.63, 122.32, 122.41, 123.28, 124.27, 124.78, 125.02, 125.85, 126.62, 127.34, 127.61, 128.07, 128.36, 128.53, 128.82, 130.42, 130.59, 130.91, 131.55, 133.43, 142.18, 148.64. MALDI-TOF MS: $m / z .983 .18\left[\mathrm{M}^{+}\right]$; calcd 982.29.

\subsection{Synthesis of 2-(4-nitrostyryl)-1-(1-methylnaphthalen-4- yl)-1H-phenanthro[9,10- $d]$ imidazole (MeNSPI)}

MeNSPI was synthesized using the methodology similar to that of NSPI. Anal. calcd for $\mathrm{C}_{34} \mathrm{H}_{23} \mathrm{~N}_{3} \mathrm{O}_{2}$ : C, 80.78; $\mathrm{H}, 4.60 ; \mathrm{N}, 8.34$. Found: C, 80.72; H, 4.56; N, 8.30. ${ }^{1} \mathrm{H}$ NMR (400 MHz, $\mathrm{CDCl}_{3}$ ) $\delta 2.30(\mathrm{~s}, 3 \mathrm{H}) 6.93(\mathrm{~d}, J=15.0 \mathrm{~Hz}, 1 \mathrm{H}), 7.05(\mathrm{t}, 1 \mathrm{H}), 7.27(\mathrm{~d}, J=$ $15.5 \mathrm{~Hz}, 1 \mathrm{H}), 7.39-7.52(\mathrm{~m}, 5 \mathrm{H}), 7.73-7.87(\mathrm{~m}, 7 \mathrm{H}), 8.15(\mathrm{~d}, J=$ $8.7 \mathrm{~Hz}, 2 \mathrm{H}), 8.75$ (t, 1H), 9.01 (d, $J=7.8 \mathrm{~Hz}, 2 \mathrm{H}) .{ }^{13} \mathrm{C}$ NMR $(100$ $\left.\mathrm{MHz}, \mathrm{CDCl}_{3}\right): \delta 22.65,115.73,122.96,124.34,124.88,126.29$, $126.87,127.11,127.69,127.85,128.21,128.46,129.07,129.49$, 129.64, 129.96, 130.43, 131.98, 132.35, 137.18, 143.88, 148.96. MS: $m / z .505 .64\left[\mathrm{M}^{+}\right]$; calcd 505.71.

2.8. Synthesis of 4-((E)-2-(1-(1-methylnaphthalen-4-yl)-1Hphenanthro[9,10- $d]$ imidazol-2-yl)vinyl)benzenamine (MeNPI)

MeNPI was synthesized using the methodology similar to that of NPI. Anal. calcd for $\mathrm{C}_{34} \mathrm{H}_{25} \mathrm{~N}_{3}$ : C, 85.89; H, 5.28; N, 8.87. Found: C, 85.86; H, 5.22; N, 8.81. ${ }^{1} \mathrm{H}$ NMR (400 MHz, $\mathrm{CDCl}_{3}$ ) $\delta 2.65(\mathrm{~s}, 3 \mathrm{H}) 6.60(\mathrm{~d}, J=8.2 \mathrm{~Hz}, 2 \mathrm{H}), 6.74(\mathrm{~s}, 2 \mathrm{H}), 6.93(\mathrm{~d}, J=$ $16.0 \mathrm{~Hz}, 2 \mathrm{H}), 7.13-7.24(\mathrm{~m}, 5 \mathrm{H}), 7.31$ (d, $J=16.0 \mathrm{~Hz}, 1 \mathrm{H}), 7.64-$ $7.80(\mathrm{~m}, 7 \mathrm{H}), 8.12(\mathrm{~d}, J=8.8 \mathrm{~Hz}, 1 \mathrm{H}), 8.48(\mathrm{~d}, J=7.6 \mathrm{~Hz}, 2 \mathrm{H}) .{ }^{13} \mathrm{C}$ NMR (100 MHz, $\mathrm{CDCl}_{3}$ ): $\delta$ 21.81, 113.65, 120.8, 122.26, 122.72, 124.27, 124.79, 125.06, 126.13, 126.38, 126.97, 127.41, 127.56, $127.88,128.37,128.64,128.91,129.92,130.27,135.07,141.72$, 146.89. MS: $m / z .475 .56\left[\mathrm{M}^{+}\right]$; calcd 475.62 .

2.9. (E)-4'-(1-(4-(2-(1-(4-Methylnaphthalen-1-yl)-1Hphenanthro[9,10- $d]$ imidazol-2-yl)vinyl)phenyl)-1 $H$ phenanthro[9,10-d] imidazol-2-yl)- $N, N$-diphenyl- $\left[1,1^{\prime}\right]$ biphenyl]-4-amine (MeNPI-PITPA)

MeNPI-PITPA was synthesized using the methodology similar to that of NPI-PITPA. Anal. calcd for $\mathrm{C}_{73} \mathrm{H}_{49} \mathrm{~N}_{5}: \mathrm{C}, 88.05 ; \mathrm{H}, 4.94 ; \mathrm{N}$, 7.06. Found: C, 88.01; H, 4.89; N, 7.01. ${ }^{1} \mathrm{H}$ NMR $(400 \mathrm{MHz}$, $\left.\mathrm{CDCl}_{3}\right) \delta 2.35(\mathrm{~s}, 3 \mathrm{H}), 6.74(\mathrm{~d}, J=16.0 \mathrm{~Hz}, 2 \mathrm{H}), 6.85(\mathrm{~s}, 4 \mathrm{H}), 7.00$ $(\mathrm{d}, J=15.0 \mathrm{~Hz}, 1 \mathrm{H}), 7.28-7.53(\mathrm{~m}, 23 \mathrm{H}), 7.62(\mathrm{~d}, J=7.4 \mathrm{~Hz}, 2 \mathrm{H})$, $7.68-7.78(\mathrm{~m}, 10 \mathrm{H}), 8.38(\mathrm{~d}, 2 \mathrm{H}), 8.75(\mathrm{t}, 2 \mathrm{H}) .{ }^{13} \mathrm{C}$ NMR $(100$ $\left.\mathrm{MHz}, \mathrm{CDCl}_{3}\right): \delta 22.43,113.61,123.38,123.39,124.26,125.27$, 125.76, 126.08, 126.83, 127.61, 128.32, 128.59, 129.05, 129.34,
129.51, 131.57, 131.89, 132.53, 132.53, 134.45, 143.16, 149.62. MALDI-TOF MS: $m / z .996 .26\left[\mathrm{M}^{+}\right]$; calcd 996.34.

\subsection{Synthesis of 2-(4-nitrostyryl)-1-(1-methoxynaphthalen-} 4-yl)-1H-phenanthro[9,10- $d]$ imidazole (OMeNSPI)

OMeNSPI was synthesized using the methodology similar to that of NSPI. Anal. calcd for $\mathrm{C}_{34} \mathrm{H}_{23} \mathrm{~N}_{3} \mathrm{O}_{3}$ : C, 78.28; H, 4.48; N, 8.08. Found: C, 78.24; H, 4.42; N, 8.02. ${ }^{1} \mathrm{H}$ NMR $(400 \mathrm{MHz}$, $\left.\mathrm{CDCl}_{3}\right) \delta 3.75(\mathrm{~s}, 3 \mathrm{H}) 6.69(\mathrm{~d}, J=15.0 \mathrm{~Hz}, 1 \mathrm{H}), 6.79(\mathrm{t}, 1 \mathrm{H}), 7.01$ (d, $J=15.5 \mathrm{~Hz}, 1 \mathrm{H}), 7.15-7.28(\mathrm{~m}, 5 \mathrm{H}), 7.49-7.63(\mathrm{~m}, 7 \mathrm{H}), 7.91$ $(\mathrm{d}, 2 \mathrm{H}), 8.51(\mathrm{t}, 1 \mathrm{H}), 8.35(\mathrm{~d}, J=8.6 \mathrm{~Hz}, 2 \mathrm{H}) .{ }^{13} \mathrm{C} \mathrm{NMR}(100 \mathrm{MHz}$, $\mathrm{CDCl}_{3}$ ): $\delta 55.64,116.06,123.29,124.67,125.13,126.61,127.19$, $127.47,128.02$, 128.17, 128.54, 128.79, 129.37, 129.97, 130.28, 130.76, 132.31, 132.68, 137.45, 144.16, 149.28. MS: $\mathrm{m} / \mathrm{z} .491 .2$ $\left[\mathrm{M}^{+}\right]$; calcd 491.27.

2.11. Synthesis of 4-((E)-2-(1-(1-methoxynaphthalen-4-yl)-1Hphenanthro[9,10- $d]$ imidazol-2-yl)vinyl)benzenamine (OMeNPI)

OMeNPI was synthesized using the methodology similar to that of NPI. Anal. calcd for $\mathrm{C}_{34} \mathrm{H}_{25} \mathrm{~N}_{3} \mathrm{O}$ : C, 83.09; H, 5.16; N, 8.58. Found: C, 83.05; H, 5.12; N, 8.56. ${ }^{1} \mathrm{H}$ NMR (400 MHz, $\mathrm{CDCl}_{3}$ ) $\delta 4.15(\mathrm{~s}, 3 \mathrm{H}), 6.16(\mathrm{~d}, J=7.6 \mathrm{~Hz}, 2 \mathrm{H}), 6.32(\mathrm{~s}, 2 \mathrm{H}), 6.51(\mathrm{~d}, J=$ $16.0 \mathrm{~Hz}, 2 \mathrm{H}), 6.69-6.80(\mathrm{~m}, 5 \mathrm{H}), 6.80(\mathrm{~d}, J=16.0 \mathrm{~Hz}, 1 \mathrm{H}), 7.20-$ $7.36(\mathrm{~m}, 7 \mathrm{H}), 7.70(\mathrm{~d}, J=8.2 \mathrm{~Hz}, 1 \mathrm{H}), 8.06(\mathrm{~d}, J=8.4 \mathrm{~Hz}, 2 \mathrm{H}) .{ }^{13} \mathrm{C}$ NMR (100 MHz, $\left.\mathrm{CDCl}_{3}\right): \delta 56.26,113.97,121.21,122.58,123.04$, 124.52, 125.17, 125.38, 125.93, 126.08, 126.43, 126.72, 127.28, $127.73,127.88,128.19,128.67,130.22,130.59$, 135.36, 142.07, 147.19. MS: $\mathrm{m} / z .521 .37\left[\mathrm{M}^{+}\right]$; calcd 521.43 .

\subsection{2. (E)-4' -(1-(4-(2-(1-(4-Methoxynaphthalen-1-yl)-1H-} phenanthro[9,10- $d]$ imidazol-2-yl)vinyl)phenyl)- $1 H$ phenanthro[9,10- $d]$ imidazol-2-yl)- $N, N$-diphenyl- $\left[1,1^{\prime}\right]$ biphenyl]-4-amine (OMeNPI-PITPA)

OMeNPI-PITPA was synthesized using the methodology similar to that of NPI-PITPA. Anal. calcd for $\mathrm{C}_{73} \mathrm{H}_{49} \mathrm{~N}_{5} \mathrm{O}: \mathrm{C}, 86.42 ; \mathrm{H}$, 4.82; N, 6.94. Found: C, 86.38; H, 4.79; N, 6.91. ${ }^{1} \mathrm{H}$ NMR (400 $\left.\mathrm{MHz} \mathrm{CDCl}_{3}\right) \delta 4.10(\mathrm{~s}, 3 \mathrm{H}), 6.62(\mathrm{~d}, J=16.0 \mathrm{~Hz}, 2 \mathrm{H}), 6.73(\mathrm{~s}, 4 \mathrm{H})$, $6.86(\mathrm{~d}, J=15.0 \mathrm{~Hz}, 1 \mathrm{H}), 7.06-7.31(\mathrm{~m}, 23 \mathrm{H}), 7.48(\mathrm{~d}, J=7.6 \mathrm{~Hz}$, $2 \mathrm{H}), 7.62-7.66(\mathrm{~m}, 10 \mathrm{H}), 8.24(\mathrm{~d}, J=8.2 \mathrm{~Hz}, 2 \mathrm{H}), 8.61(\mathrm{t}, 2 \mathrm{H}) .{ }^{13} \mathrm{C}$ NMR (100 MHz, $\left.\mathrm{CDCl}_{3}\right): \delta 55.24,114.17,123.79,123.88,124.75$, 125.74, 126.27, 126.49, 127.37, 128.09, 128.81, 129.08, 129.54, 129.83, 130.04, 130.29, 131.89, 132.06, 134.94, 143.65, 150.17. MALDI-TOF MS: $m / z .1012 .28\left[\mathrm{M}^{+}\right]$; calcd 1012.24.

\section{Results and discussion}

\subsection{Photophysical properties}

The $(E)-4^{\prime}-(1-(4-(2-(1-(n a p h t h a l e n-1-y l)-1 H$-phenanthro[9,10-d] imidazol-2-yl) vinyl) phenyl)-1 $H$-phenanthro[9,10- $d]$ imidazol-2yl)- $N, N$-diphenyl-[1,1']-biphenyl]-4-amine derivatives NPI-PITPA, MeNPI-PITPA and OMeNPI-PITPA were synthesised and characterized by ${ }^{1} \mathrm{H}$ and ${ }^{13} \mathrm{C} \mathrm{NMR}$, high resolution mass and elemental analysis. These compounds exhibit good thermal stability and the decomposition temperature with 5\% weight loss $\left(T_{\mathrm{d} 5}\right)$ has been measured as 549, 568 and $571{ }^{\circ} \mathrm{C}$ (Table 1 ). 
Table 1 Optical, thermal properties and device performances of NPI-PITPA, MeNPI-PITPA, OMeNPI-PITPA, NPI-PITPA:Ir(PPy) 3 , MeNPIPITPA:Ir(PPy $)_{3}$ and OMeNPI-PITPA:Ir(PPy) 3

\begin{tabular}{|c|c|c|c|c|c|c|}
\hline$\lambda_{\mathrm{ab}}(\mathrm{nm})(\mathrm{sol} / \mathrm{film})$ & $256,361 / 257,364$ & $258,363 / 259,366$ & $259,365 / 264,367$ & - & - & - \\
\hline$\lambda_{\mathrm{em}}(\mathrm{nm})(\mathrm{sol} / \mathrm{film})$ & $431 / 438$ & $441 / 445$ & $443 / 449$ & - & - & - \\
\hline$\phi(\operatorname{soln} /$ film $)$ & $0.86 / 0.91$ & $0.91 / 0.93$ & $0.94 / 0.97$ & - & - & - \\
\hline$V_{1000}(\mathrm{~V})$ & 3.3 & 3.2 & 2.9 & 3.0 & 2.9 & 2.7 \\
\hline$L\left(\mathrm{~cd} \mathrm{~m}^{-2}\right)$ & 13468 & 13599 & 13710 & 6883 & 7656 & 8215 \\
\hline$\eta_{\mathrm{p}}\left(\operatorname{lm~\mathrm {W}^{-1})}\right.$ & 4.2 & 4.9 & 5.1 & 26.3 & 28.8 & 30.1 \\
\hline $\operatorname{CIE}(x, y)$ & $0.15,0.09$ & $0.15,0.08$ & $0.15,0.07$ & $0.31,0.62$ & $0.31,0.62$ & $0.31,0.62$ \\
\hline $\mathrm{EL}(\mathrm{nm})$ & 437 & 442 & 443 & 429,521 & 430,522 & 425,520 \\
\hline
\end{tabular}

Differential scanning calorimetric (DSC) scan performed at $10{ }^{\circ} \mathrm{C} \min ^{-1}$ revealed a glass transition temperature $\left(T_{\mathrm{g}}\right)$ of 176 , 189 and $191{ }^{\circ} \mathrm{C}$ (Fig. 1). Owing to rigid molecular back bone and non-coplanarity geometry, the synthesized materials exhibit high $T_{\mathrm{g}}$ and $T_{\mathrm{d} 5}$ values which indicate that they could form morphologically stable amorphous films upon vacuum thermal evaporation which is highly important for device fabrication since the high $T_{\mathrm{m}}$ and $T_{\mathrm{d} 5}$ could improve the life time of devices. ${ }^{35}$ The lifetime decay curve is shown in Fig. 2 and the radiative lifetime of these compounds are $1.68 \mathrm{~ns}$ (NPI-PITPA) and $1.86 \mathrm{~ns}$ (MeNPI-PITPA) and $1.93 \mathrm{~ns}$ (OMeNPI-PITPA).

Geometry optimization of NPI-PITPA, MeNPI-PITPA and OMeNPI-PITPA has been performed by DFT/B3LYP/6-31G(d,p) level using Gaussian-03 and the optimized geometry is shown in Fig. 3 along with their corresponding molecular orbital distribution. The HOMO orbital of NPI-PITPA and OMeNPIPITPA is localized at styryl phenanthrimidazole group, while the LUMO orbital distributes on PITPA. The HOMO orbital of MeNPI-PITPA is localized at methyl naphthyl fragment and styryl moiety, while the LUMO orbital distributes majority on phenanthrimidazole fragment. The HOMO and LUMO of NPIPITPA, MeNPI-PITPA and OMeNPI-PITPA display adequate separation in electron density features which benefits the holeand electron-transport functions. ${ }^{36}$ The calculated electron and

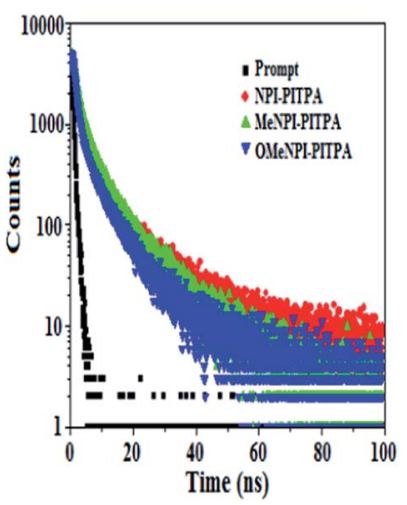

Fig. 2 Lifetime spectra of NPI-PITPA, MeNPI-PITPA and OMeNPIPITPA.
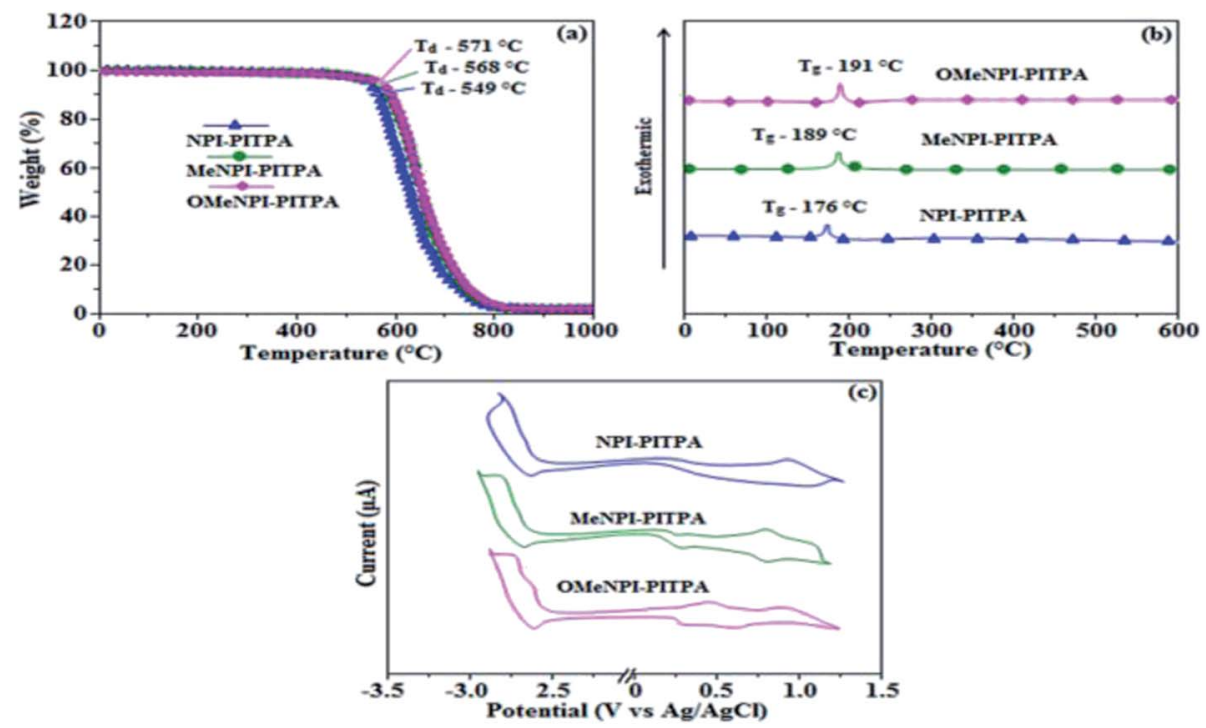

Fig. 1 (a) TGA graphs (b) DSC graphs and (c) cyclic voltammograms of NPI-PITPA, MeNPI-PITPA and OMeNPI-PITPA. 


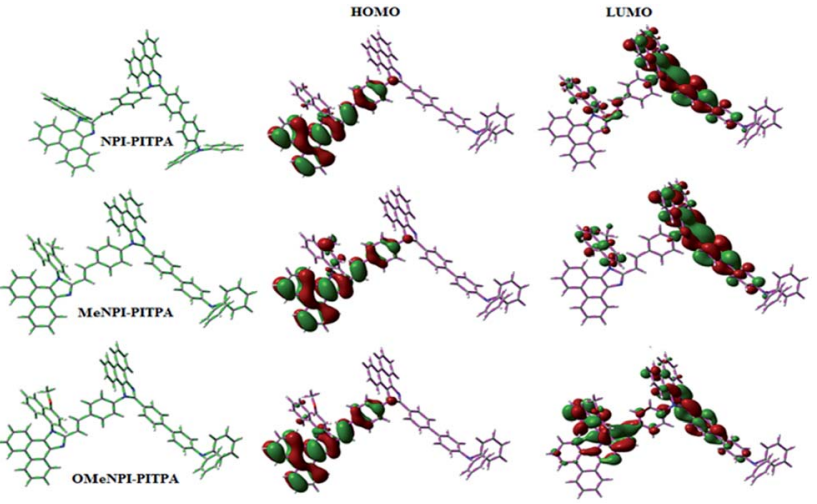

Fig. 3 Geometry optimization, HOMO and LUMO of NPI-PITPA, MeNPI-PITPA and OMeNPI-PITPA.

hole transfer integrals for OMeNPI-PITPA are 0.038 and $0.042 \mathrm{eV}$ which reveal that OMeNPI-PITPA act as bipolar material. Moreover these compounds exhibit reduction and oxidation waves revealing that these derivatives should have good electron and hole transport abilities (Fig. 1).

The electronic spectral studies of NPI-PITPA, MeNPI-PITPA and OMeNPI-PITPA have been measured in dichloromethane and the absorption and emission spectra have been displayed in Fig. 4. The absorption maxima around $256 \mathrm{~nm}$ may originate from naphthyl ring attached to nitrogen of phenanthrimidazole plane and the absorption band around $361 \mathrm{~nm}$ is assigned to $\pi$ $\rightarrow \pi^{*}$ electronic transition of the styryl phenanthrimidazole ring. This NPI-PITPA, MeNPI-PITPA and OMeNPI-PITPA derivatives show blue emission at 438, 441 and $443 \mathrm{~nm}$, respectively, in $\mathrm{CH}_{2} \mathrm{Cl}_{2}$. The emission peak shift towards a longer wavelength as the polarity of the solvent increases (Fig. S1†) and this variation is likely due to the polarization-induced spectral shift. ${ }^{37}$ The film state of NPI-PITPA, MeNPI-PITPA and OMeNPI-PITPA show a red shift of 437, 445 and $449 \mathrm{~nm}$, respectively but are

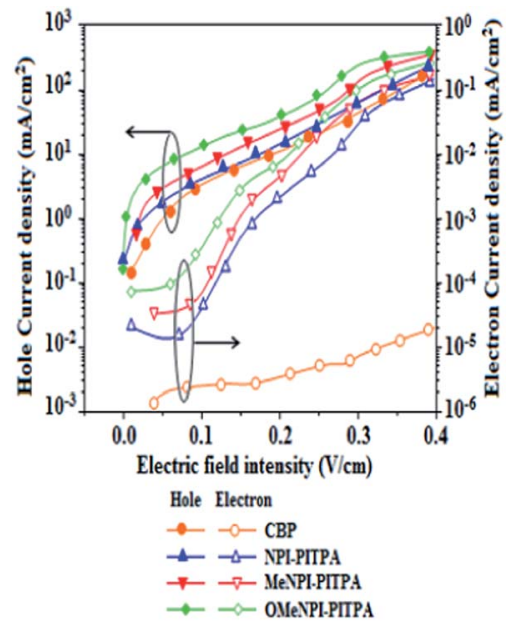

Fig. 5 Hole-only and electron-only devices based on NPI-PITPA, MeNPI-PITPA and OMeNPI-PITPA.

still localized in the blue region with a small full-width at halfmaximum (FWHM) around $52 \mathrm{~nm}$. This small FWHM implies the inconsiderable aggregation involved in its solid state and also due to elongated conjugation. ${ }^{38}$ These compounds exhibit blue emission with high quantum yield of NPI-PITPA (0.86), MeNPI-PITPA (0.91) and OMeNPI-PITPA (0.94) and the measured quantum yield in film are $0.91,0.93$ and 0.97 for NPIPITPA, MeNPI-PITPA and OMeNPI-PITPA. Such high fluorescence efficiencies are essential for efficient blue OLEDs.

The triplet energy levels are estimated to be $2.45 \mathrm{eV}$ (NPIPITPA), $2.43 \mathrm{eV}$ (MeNPI-PITPA) and $2.39 \mathrm{eV}$ (OMeNPI-PITPA) and are sufficiently high for the excitation of green phosphorescent dopants. ${ }^{32}$ The $\Delta E_{\mathrm{ST}}$ values of NPI-PITPA, MeNPI-PITPA and OMeNPI-PITPA were calculated to be $0.29 \mathrm{eV}, 0.31 \mathrm{eV}$ and $0.34 \mathrm{eV}$, respectively. The small $\Delta E_{\mathrm{ST}}$ values are advantageous for efficient energy transfer from the triplet excited state of hosts to green phosphorescent emitters. ${ }^{39}$
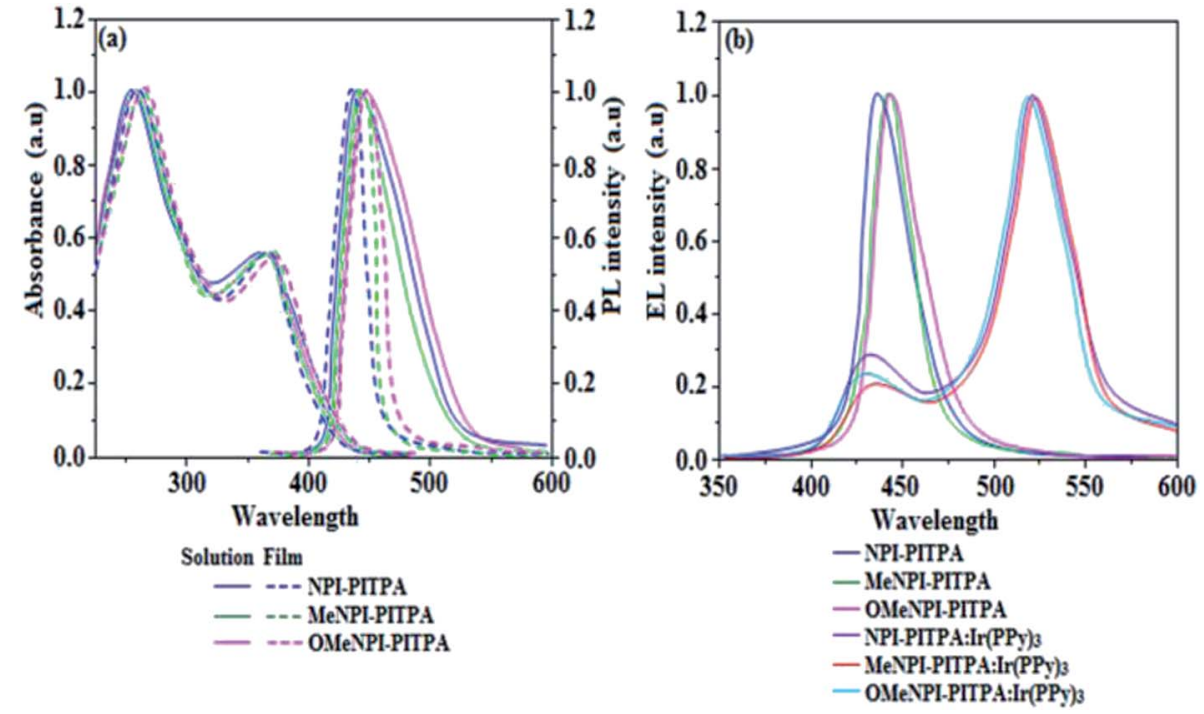

Fig. 4 (a) Normalized absorption, emission and (b) EL spectra of NPI-PITPA, MeNPI-PITPA and OMeNPI-PITPA. 
To evaluate the carrier injection and transport properties the hole-only and electron-only devices have been fabricated and the device configuration: (b) ITO/HATCN (10 nm)/NPI-PITPA/ MeNPI-PITPA/OMeNPI-PITPA (60 nm)/HATCN $(10 \mathrm{~nm}) / \mathrm{LiF}$ $(1 \mathrm{~nm}) / \mathrm{Al}(100 \mathrm{~nm})$ (hole-only device IV): (c) ITO/TPBi $(10 \mathrm{~nm}) /$ NPI-PITPA/MeNPI-PITPA/OMeNPI-PITPA $\quad\left(\begin{array}{ll}60 & \mathrm{~nm}\end{array}\right) / \mathrm{TPBi}$ $(10 \mathrm{~nm}) / \mathrm{LiF}(1 \mathrm{~nm}) / \mathrm{Al}(100 \mathrm{~nm})$ (electron-only device V). Fig. 5 shows the current density versus voltage characteristics of the hole-only and electron-only devices. The electron current density NPI-PITPA/MeNPI-PITPA/OMeNPI-PITPA based device is higher than the CBP-based device. This reveals that these materials have better electron injection and transport properties than CBP. The difference in current density between the hole-only and electron-only devices based on NPI-PITPA/MeNPIPITPA/OMeNPI-PITPA is much smaller than that based on CBP at the same voltage suggesting these materials are potential bipolar material capable of transporting electrons and holes in the devices. ${ }^{40-42}$

The observed intense blue emission and high $T_{\mathrm{g}}$ for NPIPITPA, MeNPI-PITPA and OMeNPI-PITPA suggest their suitability to serve as blue emitters in OLED applications. The device performances of the blue emitters are analysed by fabricating non-doped OLEDs with configuration of ITO/NPB (1,4-bis(1-naphthylphenylamino)-biphenyl) $(50 \mathrm{~nm}$ )/NPI-PITPA (I)/MeNPI-PITPA (II)/OMeNPI-PITPA (III) $(30 \mathrm{~nm}) / \mathrm{BCP} \quad(2,9-$ dimethyl-4,7-diphenyl-1,10-phenanthroline) $(15 \mathrm{~nm}) / \mathrm{Alq}_{3}$ (tris(8-hydroxyquinoline)aluminum) $(50 \mathrm{~nm}) / \mathrm{LiF}(1 \mathrm{~nm}) / \mathrm{Al}(100 \mathrm{~nm})$ (Fig. 6). The device performances are detailed in Table 1. It is clear from Fig. 7 that the three new born NPI-PITPA, MeNPIPITPA and OMeNPI-PITPA based devices exhibit high brightness at low voltage. The resulting blue EL spectra of the devices are very similar to the PL spectra of NPI-PITPA, MeNPIPITPA and OMeNPI-PITPA in the solid state (Fig. 4). The hole injection barriers between OMeNPI-PITPA and hole transport layer is very small and thus to combine the electron-hole radiative recombination in the emissive layer. Additionally the blue emitter OMeNPIP exhibit better thermal stability $\left(T_{\mathrm{d}}-571^{\circ} \mathrm{C} \&\right.$ $\left.T_{g}-191^{\circ} \mathrm{C}\right)$ and high quantum efficiency $(\phi-0.94 / 0.97)$. These results reveal that OMeNPI-PITPA is a potential non-doped blue light emitting material. The small injection barrier $0.26,0.38$ and 0.49 (OMeNPI-PITPA; MeNPI-PITPA; NPI-PITPA) for charge carriers may account for the observed low turn-on voltages. The OMeNPI-PITPA film fabricated by vacuum deposition exhibits a smooth surface morphology with a roughness of $0.28 \mathrm{~nm}$. After annealing at $100{ }^{\circ} \mathrm{C}$ for $7 \mathrm{~h}$, the film morphology is still unchanged (Fig. 6). The EQE of OLEDs can be calculated as follows: $\mathrm{EQE}=\eta_{\text {out }} \times \eta_{\mathrm{rc}} \times \eta_{\gamma} \times \Phi_{\mathrm{PL}}{ }^{43}$ where $\eta_{\text {out }}$ is the lightout-coupling efficiency $(20 \%), \eta_{\mathrm{rc}}$ is the product of the charge recombination efficiency, $100 \%$ if holes and electrons are fully balanced and completely recombined to form excitons, $\eta_{\gamma}$ is the efficiency of radiative exciton production $(25 \%), \Phi_{\mathrm{PL}}$ is the photoluminescence quantum yield of the emitters.

The maximum external quantum efficiency and current efficiencies of NPI-PITPA, MeNPI-PITPA and OMeNPI-PITPA based devices are 4.60, 4.70 and $4.90 \%$ and 4.8, 5.2 and $5.9 \mathrm{~cd} \mathrm{~A}^{-1}$, respectively. This result could be attributed the more balanced charge-transporting properties within the emissive layer achieved by better charge injection provided by hole transport layer. As well as having high external quantum efficiency and current efficiency, the NPI-PITPA, MeNPI-PITPA and OMeNPI-PITPA
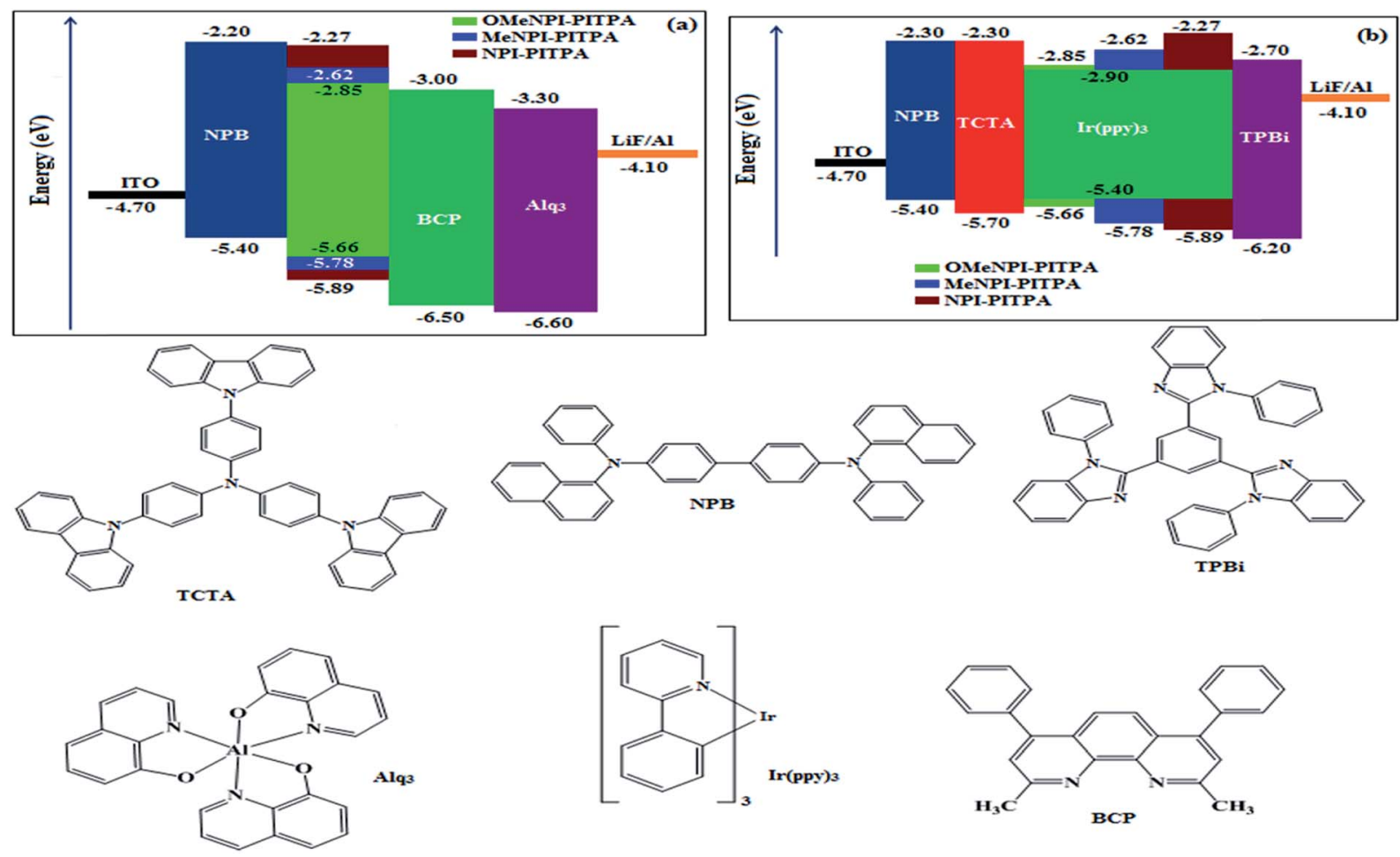

Fig. 6 Energy-level diagram of the materials used for the fabrication of (a) blue and (b) green devices. 

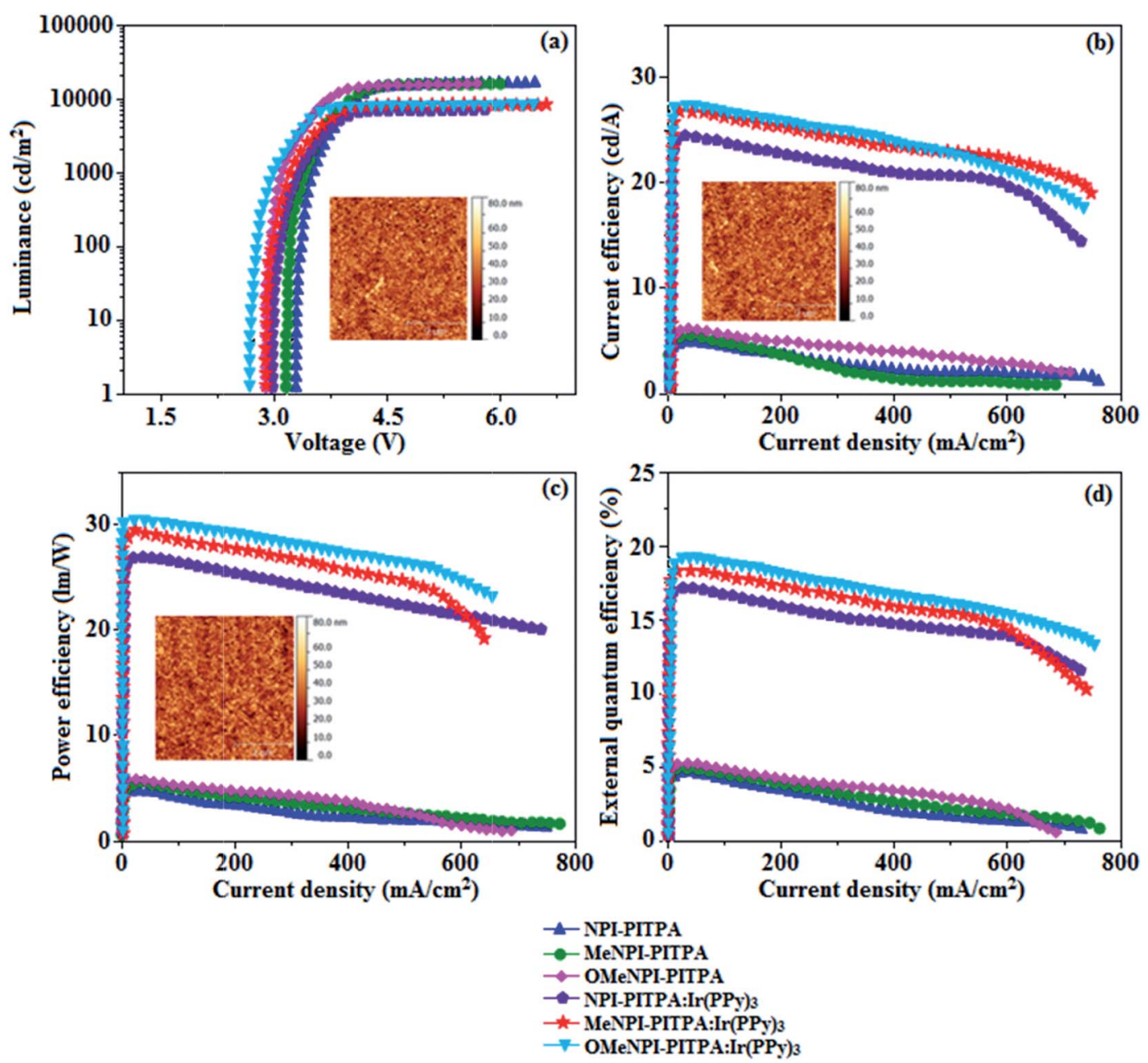

Fig. 7 Electroluminescence performances: (a) luminance versus voltage, (b) current efficiency, (c) power efficiency versus current density, (d) external quantum efficiency versus current density [inset: AFM images of NPI-PITPA, MeNPI-PITPA and OMeNPI-PITPA].

based devices also show high power efficiency of $4.2,4.9$ and $5.1 \mathrm{~lm} \mathrm{~W}^{-1}$ at low driving voltages. The non-doped devices exhibit blue emission with CIE coordinates of $(0.15,0.09-\mathrm{NPI}-$ PITPA), (0.15, 0.08 - MeNPI-PITPA) and (0.15, 0.07 - OMeNPIPITPA). Device based on OMeNPI-PITPA shows maximum luminance of $13710 \mathrm{~cd} \mathrm{~m}^{-2}$, maximum current and power efficiencies of $5.9 \mathrm{~cd} \mathrm{~A}^{-1}$ and $5.1 \mathrm{~lm} \mathrm{~W} \mathrm{~W}^{-1}$ at low turn-on voltage $(2.9 \mathrm{~V})$, respectively.

These NPI-PITPA, MeNPI-PITPA and OMeNPI-PITPA compounds are also utilised as host materials for green phosphorescent dopants in the fabricated device with configuration of ITO/NPB $(40 \mathrm{~nm}) /$ TCTA $(5 \mathrm{~nm}) / \mathrm{NPI}$-PITPA $(30 \mathrm{~nm}): 5 \mathrm{wt} \%$ $\operatorname{Ir}(\text { ppy })_{3} /$ MeNPI-PITPA $(30 \mathrm{~nm}): 5$ wt $\% \operatorname{Ir}(\text { ppy })_{3} /$ OMeNPI-PITPA $(30 \mathrm{~nm}): 5 \mathrm{wt} \% \operatorname{Ir}(\text { ppy })_{3} / \mathrm{TPBI}(50 \mathrm{~nm}) / \mathrm{LiF}(1 \mathrm{~nm}) / \mathrm{Al}(100 \mathrm{~nm})$ (Fig. 6). The device performances and EL spectra of these devices are shown in Fig. 6 and 4. The EL spectra are similar to the PL spectra of the doped thin films (Fig. 4). Device based on OMeNPI-PITPA $(30 \mathrm{~nm}): 5 \mathrm{wt} \% \operatorname{Ir}(\mathrm{ppy})_{3}$ exhibits maximum luminance of $8215 \mathrm{~cd} \mathrm{~m}^{-2}$, maximum current and power efficiencies are of $27.3 \mathrm{~cd} \mathrm{~A}^{-1}$ and $30.1 \mathrm{~lm} \mathrm{~W}^{-1}$, respectively at low turn-on voltage of $2.7 \mathrm{~V}$. The maximum external quantum efficiencies of the devices based on NPI-PITPA:Ir(ppy $)_{3}$, MeNPIPITPA:Ir(ppy $)_{3}$ and OMeNPI-PITPA:Ir(ppy $)_{3}$ are $17.0 \%, 18.3 \%$ and $19.0 \%$, respectively. The device performances reveal that NPI-PITPA, MeNPI-PITPA and OMeNPI-PITPA are universal host materials for green phosphorescent emitters.

\section{Conclusion}

We have reported the efficient newborn deep blue emitting materials NPI-PITPA, MeNPI-PITPA and OMeNPI-PITPA with D-A geometry exhibit dual charge transport properties and show excellent thermal properties with high glass-transition temperature. The deep blue emission with carrier transport abilities of NPI-PITPA, MeNPI-PITPA and OMeNPI-PITPA reveal that the non-doped devices based on these compounds exhibit maximum external quantum efficiency, current and power efficiencies as NPI-PITPA $\left(4.60 \%, 4.8 \mathrm{~cd} \mathrm{~A}^{-1}\right.$ and $\left.4.2 \mathrm{~lm} \mathrm{~W}^{-1}\right)$, MeNPI-PITPA (4.70\%, $5.2 \mathrm{~cd} \mathrm{~A}^{-1}$ and $\left.4.9 \mathrm{~lm} \mathrm{~W}^{-1}\right)$ and OMeNPIPITPA $\left(4.90 \%, 5.9 \mathrm{~cd} \mathrm{~A}^{-1}\right.$ and $\left.5.1 \mathrm{~lm} \mathrm{~W}^{-1}\right)$. These materials exhibit blue emission with CIE coordinates of $(0.15,0.09$ - NPIPITPA), (0.15, 0.08 - MeNPI-PITPA) and (0.15, 0.07 - OMeNPI- 
PITPA) at low driving voltage. These blue emissive materials with good carrier transport properties are also employed as hosts for green phosphorescent devices. The maximum external quantum efficiencies of the devices based on NPIPITPA:Ir(ppy) ${ }_{3}, \quad$ MeNPI-PITPA:Ir(ppy) ${ }_{3}$ and OMeNPIPITPA:Ir(ppy) ${ }_{3}$ are $17.0 \%, 18.3 \%$ and $19.0 \%$, respectively. The present findings demonstrate a new route to harvest efficient device performances by developing luminescent materials with D-A molecular structure.

\section{Conflicts of interest}

There are no conflicts to declare.

\section{Acknowledgements}

One of the author Dr J. Jayabharathi thank Department of Science and Technology (EMR/2014/000094), Defence Research and Development Organization (213/MAT/10-11), Council of Scientific and Industrial Research [No. 01/(2707)/13EMR-II], University Grant Commission (36-21/2008) and Nano Mission (SR/NM/NS-1001/2016) for financial support. Authors would like to thank Mr P. Justin Jesuraj for scientific discussions related to device performances.

\section{References}

1 (a) C. W. Tang and S. A. Vanslyke, Appl. Phys. Lett., 1987, 51, 913-915; (b) C. C. Wu, Y. T. Lin, K. T. Wong, R. T. Chen and Y. Y. Chien, Adv. Mater., 2004, 16, 61-65; (c) M. T. Lee, C. H. Liao, C. H. Tsai and C. H. Chen, Adv. Mater., 2005, 17, 2493-2497; (d) H. B. Wu, L. Ying, W. Yang and Y. Cao, Chem. Soc. Rev., 2009, 38, 3391-3400; (e) M. A. Baldo, M. E. Thompson and S. R. Forrest, Nature, 2000, 403, 750753; (f) J. Kido, M. Kimura and K. Nagai, Science, 1995, 267, 1332-1334.

2 K. C. Wu, P. J. Ku, C. S. Lin, H. T. Shih, F. I. Wu, M. J. Huang, J. J. Lin, I. C. Chen and C. H. Cheng, Adv. Funct. Mater., 2008, 18, 67-75.

3 P. E. Burrows, G. Gu, V. Bulovic, Z. Shen, S. R. Forrest and M. E. Thompson, IEEE Trans. Electron Devices, 1997, 44, 1188-1203.

4 (a) L. S. Hung and C. H. Chen, Mater. Sci. Eng., R, 2002, 39, 143-222; (b) C. H. Chen, C. W. Tang, J. Shi and K. P. Klubek, Macromol. Symp., 1998, 125, 49-58.

5 M. R. Zhu and C. L. Yang, Chem. Soc. Rev., 2013, 42, 49634976.

6 J. P. J. Markham, E. B. Namdas, T. D. Anthopoulos, I. D. W. Samuel, G. R. Richards and P. L. Burn, Appl. Phys. Lett., 2004, 85, 1463-1465.

7 H. J. Bolink, E. Coronado, S. G. Santamaria, M. Sessolo, N. Evans, C. Klein, E. Baranoff, K. Kalyanasundaram, M. Graetzel and M. K. Nazeeruddin, Chem. Commun., 2007, 3276-3278.

8 W. Y. Hung, L. C. Chi, W. J. Chen, Y. M. Chen, S. H. Chou and K. T. Wong, J. Mater. Chem., 2010, 20, 10113-10119.
9 E. B. Namdas, T. D. Anthopoulos, D. W. Samuel, M. J. Frampton, S. C. Lo and P. L. Burn, Appl. Phys. Lett., 2005, 86, 161104-161106.

10 G. Zhanga, F. I. Wub, X. Jianga, P. Suna and C. H. Cheng, Synth. Met., 2010, 160, 1906-1911.

11 H. H. Chou and C. H. Cheng, Adv. Mater., 2010, 22, 24682471.

12 S. J. Su, H. Sasabe, T. Takeda and J. Kido, Chem. Mater., 2008, 20, 1691-1693.

13 H. H. Chou, Y. H. Chen, H. P. Hsu, W. H. Chang, Y. H. Chen and C. H. Cheng, Adv. Mater., 2012, 24, 5867-5871.

14 M. A. Baldo, M. E. Thompson and S. R. Forrest, Nature, 2000, 403, 750-753.

15 D. Kenneth, S. Jianmin, S. Nigel, F. Eric and C. M. David, Inorg. Chem., 2005, 44, 4445-4447.

16 A. Tsuboyama, H. Iwawaki, M. Furugori, T. Mukaide, J. Kamatani, S. Igawa, T. Moriyama, S. Miura, T. Takiguchi, S. Okada, M. Hoshino and K. Ueno, J. Am. Chem. Soc., 2003, 125, 12971-12979.

17 M. Zhu and C. Yang, Chem. Soc. Rev., 2013, 42, 4963-4976.

18 (a) W. Y. Lai, Q. Y. He, R. Zhu, Q. Q. Chen and W. Huang, Adv. Funct. Mater., 2008, 18, 265-276; (b) L. Wang, Y. Jiang, J. Luo, Y. Zhou, J. H. Zhou, J. Wang, J. Pei and Y. Cao, Adv. Mater., 2009, 21, 4854-4858; (c) L. Xiao, Z. Chen, B. Qu, J. Luo, S. Kong, Q. Gong and J. Kido, Adv. Mater., 2011, 23, 926-952; (d) C. G. Zhen, Y. F. Dai, W. J. Zeng, Z. Ma, Z. K. Chen and J. Kieffer, Adv. Funct. Mater., 2011, 21, 699707.

19 (a) K. Wang, F. C. Zhao, C. G. Wang, S. Y. Chen, D. Chen, H. Y. Zhang, Y. Liu, D. G. Ma and Y. Wang, Adv. Funct. Mater., 2013, 23, 2672-2680; (b) K. Wang, S. P. Wang, J. B. Wei, S. Y. Chen, D. Liu, Y. Liu and Y. Wang, J. Mater. Chem. C, 2014, 2, 6817-6826.

20 Y. Kawamura, S. Yanagida and S. R. Forrest, J. Appl. Phys., 2002, 92, 87-93.

21 F. Shen, H. Xia, C. Zhang, D. Lin, L. He and Y. Ma, J. Phys. Chem. B, 2004, 108, 1014-1019.

22 J. Jayabharathi, P. Sujatha, V. Thanikachalam, P. Jeeva and S. Panimozhi, Ind. Eng. Chem. Res., 2017, 56, 6952-6961.

23 J. Jayabharathi, V. Thanikachalam, E. Sarojpurani and P. Jeeva, Ind. Eng. Chem. Res., 2017, 56, 5325-5338.

24 V. Thanikachalam, E. Sarojpurani and J. Jayabharathi, J. Photochem. Photobiol., A, 2017, 342, 59-77.

25 V. Thanikachalam, E. Sarojpurani, J. Jayabharathi and P. Jeeva, New J. Chem., 2017, 41, 2443-2457.

$26 \mathrm{~V}$. Thanikachalam, P. Jeeva and J. Jayabharathi, RSC Adv., 2017, 7, 13604-13614.

27 V. Thanikachalam, P. Jeeva and J. Jayabharathi, ChemistrySelect, 2017, 2, 1860-1870.

28 J. Jayabharathi, A. Prabhakaran, V. Thanikachalam and P. Jeeva, New J. Chem., 2016, 40, 8768-8777.

29 J. Jayabharathi, A. Prabhakaran, V. Thanikachalam, P. Jeeva and M. Sundharesan, Ind. Eng. Chem. Res., 2016, 55, 80878095.

30 J. Jayabharathi, A. Prabhakaran, V. Thanikachalam and M. Sundharesan, RSC Adv., 2016, 6, 62208-62217. 
31 J. Jayabharathi, A. Prabhakaran, V. Thanikachalam and M. Sundharesan, ChemistrySelect, 2016, 1, 2642-2651.

32 M. J. Frisch, G. W. Trucks, H. B. Schlegel, G. E. Scuseria, M. A. Robb, J. R. Cheeseman, J. A. Montgomery, T. Vreven, K. N. Kudin, J. C. Burant, J. M. Millam, S. S. Iyengar, J. Tomasi, V. Barone, B. Mennucci, M. Cossi, G. Scalmani, N. Rega, G. A. Petersson, H. Nakatsuji, M. Hada, M. Ehara, K. Toyota, R. Fukuda, J. Hasegawa, M. Ishida, T. Nakajima, Y. Honda, O. Kitao, H. Nakai, M. Klene, X. Li, J. E. Knox, H. P. Hratchian, J. B. Cross, V. Bakken, C. Adamo, J. Jaramillo, R. Gomperts, R. E. Stratmann, O. Yazyev, A. J. Austin, R. Cammi; C. Pomelli, J. W. Ochterski, P. Y. Ayala, K. Morokuma, G. A. Voth, P. Salvador, J. J. Dannenberg, V. G. Zakrzewski, S. Dapprich, A. D. Daniels, M. C. Strain, O. Farkas, D. K. Malick, A. D. Rabuck, K. Raghavachari, J. B. Foresman, J. V. Ortiz, Q. Cui, A. G. Baboul, S. Clifford, J. Cioslowski, B. B. Stefanov, G. Liu, A. Liashenko, P. Piskorz, I. Komaromi, R. L. Martin, D. J. Fox, T. Keith, M. A. A. Laham, C. Y. Peng, A. Nanayakkara, M. Challacombe, P. M. W. Gill, B. Johnson, W. Chen, M. W. Wong, C. Gonzalez and J. A. Pople, Gaussian 09 (Revision A.02), Gaussian, Inc., Wallingford, CT, 2009.

33 M.-S. Tsai, Y.-C. Hsu, J. T. Lin, H.-C. Chen and C.-P. Hsu, J. Phys. Chem. C, 2007, 111, 18785-18793.

34 Z. Gao, Y. Liu, Z. Wang, F. Shen, H. Liu, G. Sun, L. Yao, Y. Lv, P. Lu and Y. Ma, Chem.-Eur. J., 2013, 19, 2602-2605.
35 C. Fan, Y. H. Chen, Z. Q. Jiang, C. L. Yang, C. Zhong, J. G. Qin and D. G. Ma, J. Mater. Chem., 2010, 20, 3232-3237.

36 (a) L. Duan, J. Qiao, Y. D. Sun and Y. Qiu, Adv. Mater., 2011, 23, 1137-1144; (b) C. J. Zheng, J. Wang, J. Ye, M. F. Lo, X. K. Liu, M. K. Fung, X. H. Zhang and C. S. Lee, Adv. Mater., 2013, 25, 2205-2211; (c) D. D. Zhang, L. Duan, Y. L. Li, H. Y. Li, Z. Y. Bin, D. Q. Zhang, J. Qiao, G. D. Dong, L. D. Wang and Y. Qiu, Adv. Funct. Mater., 2014, 24, 3551-3561.

37 V. Bulovic, A. Shoustikov, M. A. Baldo, E. Bose, V. G. Kozlov, M. E. Thomoson and S. R. Forrest, Chem. Phys. Lett., 1998, 287, 455-460.

38 K. C. Wu, P. J. Ku, C. S. Lin, H. T. Shih, F. I. Wu, M. J. Huang, J. J. Lin, I. C. Chen and C. H. Cheng, Adv. Funct. Mater., 2008, 18, 67-75.

39 C. Li, S. Wang, W. Chen, J. Wei, G. Yang, K. Ye, Y. Liu and Y. Wang, Chem. Commun., 2015, 51, 10632-10635.

40 Y. Liu, L. S. Cui, M. F. Xu, X. B. Shi, D. Y. Zhou, Z. K. Wang, Z. Q. Jiang and L. S. Liao, J. Mater. Chem. C, 2014, 2, 24882495.

41 Y. H. Lou, M. F. Xu, L. Zhang, Z. K. Wang, S. Naka, H. Okada and L. S. Liao, Org. Electron., 2013, 14, 2698-2704.

42 Z. Wang, Y. Lou, S. Naka and H. Okada, Appl. Phys. Lett., 2011, 98, 063302-063304.

43 V. Jankus, C. J. Chiang, F. Dias and A. P. Monkman, Adv. Mater., 2013, 25, 1455-1459. 